\title{
Landing patterns in netball: analysis of an international game
}

\author{
Diana Hopper, Sing Kai Lo*, Catherine Kirkhamt and Bruce Elliottł \\ School of Physiotherapy, Curtin University of Technology, Australia, ${ }^{*}$ Chang Gung Medical College, Taiwan;

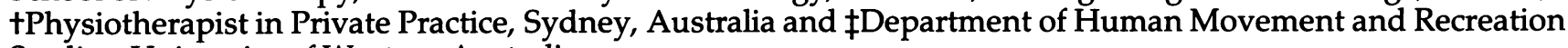 \\ Studies, University of Western Australia
}

\begin{abstract}
The passing and landing patterns among netball players were investigated by examining all the 595 passes in an international match between Australia and New Zealand. Intra-class correlations were used to test inter-observer reliability. The independence of two variables was tested using a Pearson $\chi^{2}$ test and a contingency coefficient was used to assess the degree of association between variables. An inter-rater reliability in the identification of movement patterns was 0.99. Most of the landings observed in this match were on the forefoot and not the hindfoot as generally reported in controlled experiments. Only $14 \%$ of the players leapt to receive a pass compared with $76 \%$ reported earlier under controlled environments. The distribution of passing techniques unexpectedly showed that approximately $50 \%$ of all the players did not reach for the ball as it was thrown directly to them. However, over $70 \%$ of the players threw straight passes which were mainly received in the chest quadrant and other types of passes such as loop, bounce and rebound were used less frequently. Nearly $50 \%$ of all players used a right-handed pass to dispose of the ball, while the next most popular pass was to use both hands $(40.2 \%)$. Landing and passing patterns differed between players in different positions. Footfall patterns on landing after a catch were associated with the trajectory of the ball.
\end{abstract}

Keywords: Netball, injury, footfall patterns, landing patterns

Netball is a dynamic, fast, skilful and predominantly female team sport. In Australia it attracts more than half a million registered players from the young to the middle-aged and from the unskilled to the internationally highly skilled player. Many of the skills involve explosive movements, quick changes of directions, different types of passes plus a variety of ways to receive and dispose of the ball within a 3-s time frame. Despite the fact that landings have been associated with both acute and chronic injuries as a result of the large forces on each foot ${ }^{1,2}$, landing techniques have received far less attention than the mechanics of other skills in the game.

Landing techniques are complex as they are

Address for correspondence: Diana Hopper, School of Physiotherapy, Curtin University of Technology, Selby Street, Shenton Park, 6008, Australia

(C) 1992 Butterworth-Heinemann Ltd 0306-3674/92/020101-06 influenced by both extrinsic and intrinsic factors. The extrinsic factors include the position of the team and opposition players, height and direction of movement towards the ball, footfall patterns, receipt and disposal of the ball, and the relationship between the court surface and the shoe. Besides these external factors, the player is also required to integrate the intrinsic demands of neuromuscular coordination, spatial orientation and proprioception during this complex task of landing. The ultimate movement is restricted by the footwork rule of a maximum of one-and-a-half steps while in possession of the ball. Therefore, upon landing after receiving the ball, a player must decelerate rapidly and assume a position which affords sufficient stability so that the footwork rule is not infringed ${ }^{4}$.

Attempts to investigate different landing patterns and passing techniques associated with footwork rules have been limited to the controlled laboratory environment. In early laboratory studies, Steele and Milburn carried out kinematic and kinetic analyses of landing patterns by examining the footfall patterns of 21 skilled centre-court netball players using four different types of footwear ${ }^{5,6}$. Different footfall patterns of landing were demonstrated by the players during a typical attacking movement. The most frequent footfall pattern demonstrated for all conditions was impact of the ground with the heel of the foot $(83.6 \%)$. The forefoot made initial contact with the ground in $6.3 \%$ of landings while the midfoot made contact in $2.5 \%$ of landings.

In the same study, Steele and Milburn ${ }^{5}$ also found that players varied their approach to receive the ball from a typical netball pass. Most of the subjects (75.9\%) performed a leap approach to receive the ball as compared with the $16.5 \%$ who used a hop approach. A further $7.6 \%$ used a mixture of the leap and hop approach. Moreover, the subjects consistently used one approach technique on the dominant limb and a different technique for landing on the non-dominant limb.

In a later study to examine the footfall patterns after receiving a high pass, Steele and Milburn ${ }^{2}$ found that seven of the ten subjects landed on the forefoot while only three subjects made initial contact with the heel of the foot. Steele and Lafortune ${ }^{4}$ also concluded that further research must be conducted into the footfall patterns on impact loadings in netball. 
To date, no research has addressed the integration of landing techniques with footfall patterns, different positional plays, type of pass, movement patterns to receive and dispose of the ball, in the game situation. The purpose of this study was therefore to identify at an international level: (1) the typical landing pattern and the type of passing technique used; (2) the association between each of the landing patterns and passing technique variables with different positional play; (3) the three-way relationship between typical passing technique, landing pattern and position of the player.

\section{Methods}

\section{Subjects}

An Australian Broadcasting Corporation videotape recording of the tritest series was used to analyse the match between Australia and New Zealand on 14 May 1986 in Sydney, Australia. Sixteen international players were studied (seven from the Australian team and nine from the New Zealand team, as two players were substituted due to on-court injuries). The match consisted of two 20 -min halves.

\section{Procedure}

A National NV G25 video with a variable-speed playback and freeze-frame facility was used to analyse the individual passing and landing patterns.

In the game, each pass was analysed by observing:

1. The position of the player receiving the pass;

2. The team of that player;

3. Variables related to passing and receiving the ball:

(a) type of pass

(b) direction of movement towards the ball

(c) height of the catch (in relation to the player's body)

(d) receipt and disposal of the ball (catch and throw handedness);

4. Variables related to landing patterns:
(a) footfall pattern
(b) movement pattern towards the ball
(c) side of landing (footfall).

Under the category 'movement pattern towards the ball', a hop was defined as landing on the take-off limb and a leap was defined as landing on the foot opposite to the take-off limb $b^{5}$. Both a hop and a leap indicate a stride with elevation. On the other hand, a jump is confined to elevation rather than a stride. A skip is a movement which usually involves sideways motion with little elevation and almost a two-foot landing where one foot lands followed almost immediately by the other foot. A run differs in that the player continues the running motion on receiving the pass whereas a step is performed at a walk-pace with minimal elevation.

The pass was not counted when an infringement occurred or when a catch was not completed. Landings after the ball was tossed-up by the umpire were not included in the analysis. One observer analysed all the passes. Another observer then analysed six randomly selected 5-min intervals from the videotape to establish inter-observer reliability.

\section{Statistical analysis}

The intra-class correlation was used to measure inter-observer reliability ${ }^{7}$. Frequency tables were used for descriptive purposes. The independence of two variables was tested by using the Pearson $\chi^{2}$ test. The contingency coefficient was used to assess the degree of association between variables. The above statistical techniques were used because of the unordered categorical nature of the data collected. All hypotheses were tested at the $5 \%$ significance level.

\section{Results}

The inter-rater reliability for the study sample was 0.99 . This high degree of agreement between the two observers was probably a result of the precise and clear definition of passing and movement types made before the study.

A total of 595 passes were observed in the game. The proportion of passes made by the two teams and by each position are reported in Table 1 . The result was a win for the Australian team by 35 goals to 19 . The number of passes made by the New Zealand team $(39.3 \%$ of total) was less than that of the Australian team. The defence players (goal defence and goal keeper) of both teams had fewer passes than attacking (goal shooter and goal attack) and mid-field players (wing attack, centre and wing defence).

The distributions of landing patterns and passing techniques are presented in Table 2. Forefoot landing was the most preferred landing pattern $(57.3 \%)$ with only a small percentage $(8.1 \%)$ landing on their hindfoot. Landing on the right foot $(32.4 \%)$ was slightly more frequent than left foot landings (26.1\%). Symmetrical landings were common when players landed on two feet (23.9\%). Although most of the approaches to receive the ball involved horizontal elevation (i.e. hop and leap $29.4 \%$ ), $25.0 \%$ of the passes were received with the foot planted, and a similar $24.7 \%$ caught the ball following a jump. Low-elevation movements (i.e. skip and run) toward the ball were observed $15.8 \%$ of the time.

The most frequent type of pass was straight $(73.1 \%)$ where the ball was thrown in a horizontal

Table 1. Percentage passes by team and by position $(n=$ 595)

\begin{tabular}{llr}
\hline Team & Australia & 60.7 \\
Position & Gow Zealand & 39.3 \\
& Goal shooter & 18.5 \\
& Goal attack & 16.0 \\
& Wing attack & 18.5 \\
& Centre & 20.0 \\
& Wing defence & 11.3 \\
& Goal defence & 11.3 \\
& Goal keeper & 4.4 \\
\hline
\end{tabular}


Table 2. Distributions of landing patterns and passing techniques $(n=595)$

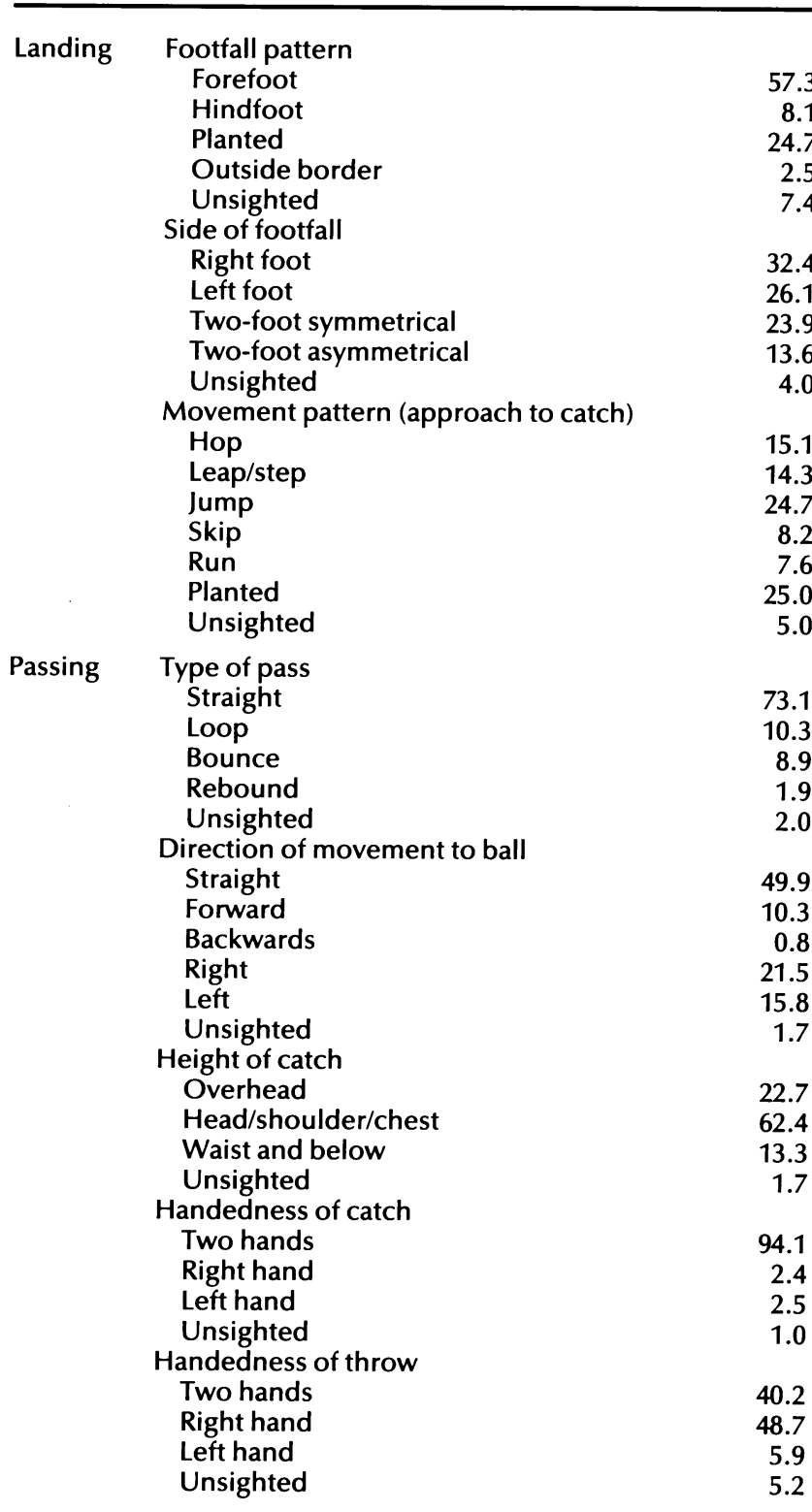

Values are percentages

direction to the player compared with the other types of passes such as a loop $(10.3 \%)$, bounce $(8.9 \%)$ and rebound $(1.9 \%)$.

Players' movements to reach the ball demonstrated an interesting pattern. Almost half $(49.9 \%)$ of the passes were directed at the players so that they did not have to reach for the ball. Of the other passes, players generally had to reach to either the right $(21.5 \%)$ or left $(15.8 \%)$ sides to catch the ball. Only $10.3 \%$ of the catches required the player to move forward towards the direction of the pass to receive the ball.

Most of the passes were caught in the chestshoulder-head quadrant $(62.4 \%)$ with $22.7 \%$ passes being caught overhead. Players used both hands to catch the ball on almost every occasion $(94.1 \%)$. but they predominantly used their right hands $(48.7 \%)$ or both hands to dispose of the ball $(40.2 \%)$.

Table 3 shows the cross-tabulation of passing and landing patterns by positional play where only those variables significantly associated with position are reported. The two passing/receiving variables which were not significant and therefore were not included in the table were reach $\left(\chi_{8}^{2}=11.14, P=0.194\right)$ and hand-catch $\left(\chi_{4}^{2}=4.08, P=0.395\right)$.

From Table 3, it can be seen that straight passes were the favoured technique of almost all players ( $72.8 \%$ of total passes for all players). Compared with attacking and mid-field players, defensive players caught the ball more often from rebounds $(8.7 \%)$ as would be expected. Bounce passes were more frequently used than the loop passes by attacking players $(13.3 \%$ versus $5.0 \%)$.

The link between height of pass and positional play is obvious. On average, mid-fielders caught the ball between the head and waist more often $(67.5 \%)$ than other players. On the other hand, defensive players caught more overhead passes $(34.0 \%)$ than other players, while attacking players received more passes below the waist $(18.5 \%)$ than for other positions.

Throwing patterns in both the attack and mid-field positions showed that two-handed $(47.7 \%$ and $47.2 \%$ respectively) and right-handed $(47.7 \%$ and $44.5 \%$ respectively) passes were almost equally favoured, whereas defensive players preferred the righthanded pass $(81.3 \%)$.

Table 3 also shows that defence players very often landed on their right foot but very seldom landed on both feet. Attacking and mid-field players landed on both feet significantly more than defensive players. These landings were generally symmetrical for attacking players and a similar percentage of symmetrical and asymmetrical landings were recorded for mid-field players.

Although landing on the forefoot was the most commonly used technique by the players irrespective of their position, the $48.6 \%$ of forefoot landings for attacking players was not as high as those by mid-field $(67.6 \%)$ and defensive players $(68.7 \%)$. Attacking players, who are responsible for shooting goals, had more landings with a planted foot when receiving the ball $(43.4 \%)$.

While a jump pattern was the most commonly observed way to approach the ball by mid-field and defensive players, $42.5 \%$ of the movements towards the ball by attacking netballers were with one foot in a planted position. Other common movement patterns used were a hop $(19.4 \%)$ by mid-fielders and leap $(20.7 \%)$ by defensive players. Both of these positions demonstrated a similar preference to a skip or running (19.7\% and $18.4 \%$ respectively) approach to the ball.

Table 4 . shows the significance and degree of association (contingency coefficient) between the landing and the passing/receiving variables by positions. A general pattern is observed, namely that, regardless of position, there is a significant association between (1) direction of movement and all the landing variables, (2) type of pass and all landing variables except footside, (3) height of the catch and all landing variables except footside. It must be 
Table 3. Distributions of landing and receiving patterns by positions (read percentages down each column for each landing/receiving variable)

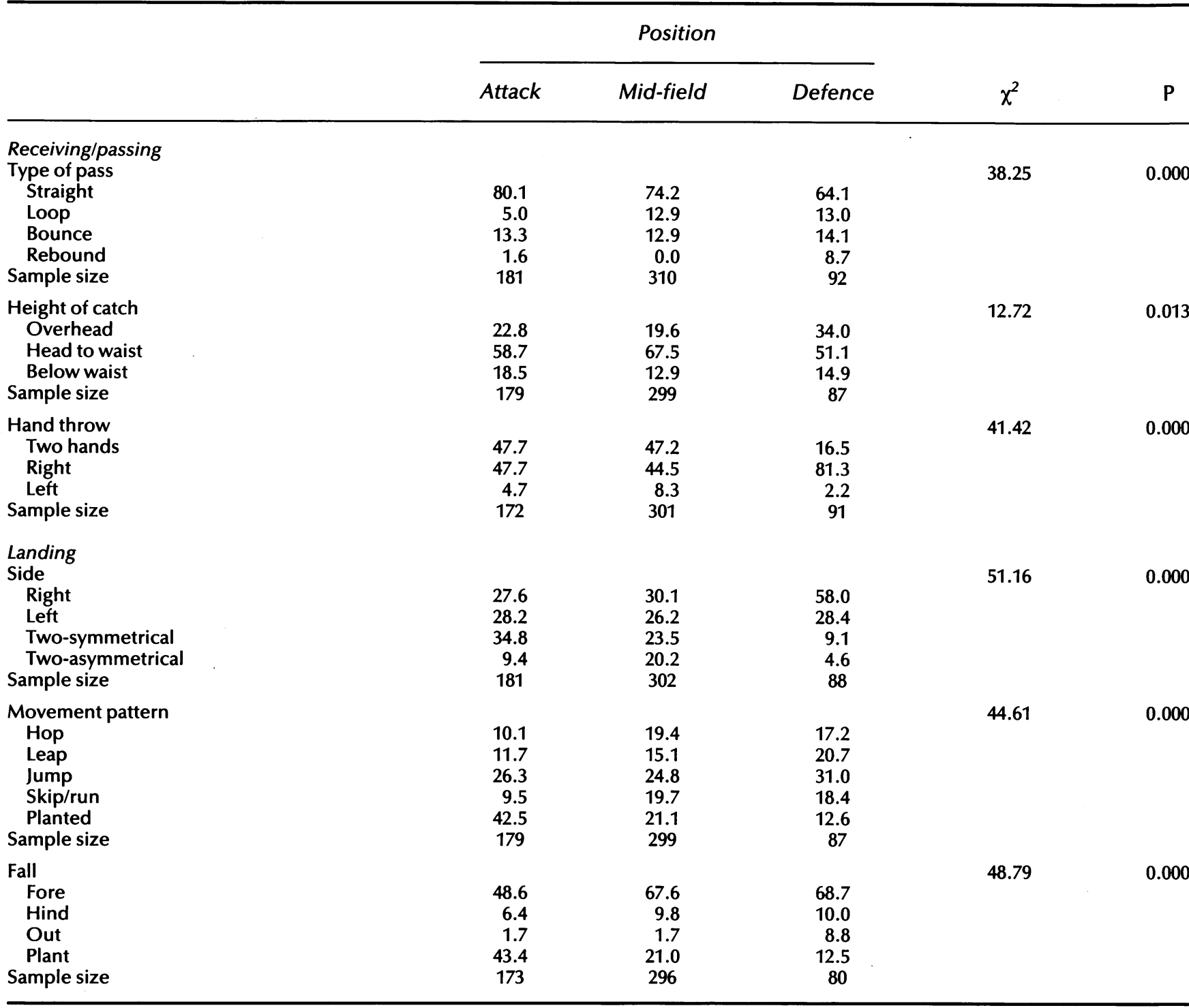

Some of the observations were unclear due to the angle of the video camera

mentioned here that the significance of a correlation coefficient depends not only on its magnitude but also on the sample size. In this study, as would be the case in many game situations, there were many more passing/receiving plays by mid-fielders (296) than by defensive players (94). Hence, the two contingency coefficients in Table 4 considered practically not significant could be regarded as practically significant because they are both 0.4 or above, which is higher than almost every other coefficient in the table but not statistically significant only because both were demonstrated by defence players. On the other hand, the two coefficients considered practically significant should be treated practically as not significant as they are both below 0.25 which is lower than all other coefficients in the table, but statistically significant because the sample sizes were relatively large for these comparisons.
The significant associations found in Table 4 between landing and passing/receiving patterns were investigated further and presented in Table 5. The breakdown by positional play was not necessary as significance was consistent between different positions. No $\chi^{2}$ statistic was shown in Table 5 as the associations are all significant.

Footfall patterns varied for different types of pass. A player who received a straight or looped pass was more likely to land on their forefoot $(66.3 \%$ and $82.8 \%$ respectively) than any other part of the foot, whereas a player receiving a bounce pass landed with the foot planted (58.2\%). On the other hand, when a player had to catch the ball from overhead or the region of the chest, she was more likely to land on her forefoot (88.4\% and $62.4 \%$ respectively), but catching the ball below the waist was usually performed with one foot planted. The most likely footfall pattern 
Table 4. Contingency coefficient between landing and passing variables by position

\begin{tabular}{|c|c|c|c|c|}
\hline \multirow[b]{2}{*}{$\begin{array}{l}\text { Passing } \\
\text { variables }\end{array}$} & \multirow[b]{2}{*}{ Position } & \multicolumn{3}{|c|}{ Landing variables } \\
\hline & & Footfall & Foot side & $\begin{array}{c}\text { Movement } \\
\text { pattern }\end{array}$ \\
\hline \multirow[t]{3}{*}{ Type of pass } & Attack & $\begin{array}{c}0.309 \\
(0.016)\end{array}$ & n.s. & $\begin{array}{c}0.353 \\
(0.022)\end{array}$ \\
\hline & Mid-field & $\begin{array}{c}0.348 \\
(0.000)\end{array}$ & $\begin{array}{c}0.223 \\
(0.023)^{*}\end{array}$ & $\begin{array}{c}0.390 \\
(0.000)\end{array}$ \\
\hline & Defence & $\begin{array}{c}0.472 \\
(0.006)\end{array}$ & n.s. & $\begin{array}{c}0.532 \\
(0.001)\end{array}$ \\
\hline \multirow[t]{3}{*}{$\begin{array}{l}\text { Direction of } \\
\text { movement }\end{array}$} & Attack & $\begin{array}{c}0.373 \\
(0.002)\end{array}$ & $\begin{array}{c}0.381 \\
(0.001)\end{array}$ & $\begin{array}{c}0.402 \\
(0.009)\end{array}$ \\
\hline & Mid-field & $\begin{array}{c}0.271 \\
(0.040)\end{array}$ & $\begin{array}{c}0.276 \\
(0.025)\end{array}$ & $\begin{array}{c}0.415 \\
(0.000)\end{array}$ \\
\hline & Defence & $\begin{array}{l}0.396 \\
(0.246) \dagger\end{array}$ & $\begin{array}{c}0.447 \\
(0.037)\end{array}$ & $\begin{array}{c}0.497 \\
(0.099)+\end{array}$ \\
\hline \multirow[t]{3}{*}{$\begin{array}{l}\text { Height of } \\
\text { catch }\end{array}$} & Attack & $\begin{array}{c}0.444 \\
(0.000)\end{array}$ & n.s. & $\begin{array}{c}0.526 \\
(0.000)\end{array}$ \\
\hline & Mid-field & $\begin{array}{c}0.332 \\
(0.000)\end{array}$ & n.s. & $\begin{array}{c}0.430 \\
(0.001)\end{array}$ \\
\hline & Defence & $\begin{array}{c}0.511 \\
(0.000)\end{array}$ & n.s. & $\begin{array}{c}0.504 \\
(0.001)\end{array}$ \\
\hline Hand catch & $\begin{array}{l}\text { Attack } \\
\text { Mid-field } \\
\text { Defence }\end{array}$ & $\begin{array}{l}\text { n.s. } \\
\text { n.s. } \\
\text { n.s. }\end{array}$ & $\begin{array}{l}\text { n.s. } \\
\text { n.s. } \\
\text { n.s. }\end{array}$ & $\begin{array}{l}\text { n.s. } \\
\text { n.s. } \\
\text { n.s. }\end{array}$ \\
\hline \multirow[t]{2}{*}{ Hand throw } & $\begin{array}{l}\text { Attack } \\
\text { Mid-field }\end{array}$ & $\begin{array}{l}\text { n.s. } \\
0.244 \\
(0.040)^{*}\end{array}$ & $\begin{array}{l}\text { n.s. } \\
\text { n.s. } \\
\text { n.s. }\end{array}$ & $\begin{array}{l}\text { n.s. } \\
\text { n.s. } \\
\text { n.s. }\end{array}$ \\
\hline & Defence & n.s. & n.s. & n.s. \\
\hline
\end{tabular}

Values in parentheses are $P$ values; *practically significant; tpractically not significant; n.s., not significant

when a player moved to reach for a straight pass was a two-foot symmetrical landing (33.9\%). When a player was forced to move forward, backward and to the right, the footfall landing pattern was also on the right side.

Table 5 also shows the relationship between the type of pass and movement patterns. Straight passes were mostly received by either a jump (29.7\%) or a planted foot $(24.2 \%)$ whereas a hop was used more frequently $(35.6 \%)$ to receive a loop pass. When a player moved straight or forwards to the ball, the foot was most frequently planted $(35.6 \%$ and $29.3 \%$, respectively). A hop (29.0\%) was used more often when a player moved to the right to reach the ball, but when moving to the left they mainly executed a leap/step $(22.8 \%)$ approach. Movement patterns appeared also to be influenced by the height of the catch, $58 \%$ of overhead passes being caught by jumping. Passes received from the head and below were more frequently received with the foot planted.

\section{Discussion}

Generally, the types of landings recorded in the game environment were not the same as those found under controlled simulated laboratory testings. Landing on the forefoot $(57.3 \%)$ was the most commonly used technique by most of the players. Hindfoot landing was unexpectedly rare for all players, irrespective of their position. These findings are different from the laboratory experiment reported by Steele and Milburn $^{5}$ where $83.6 \%$ of the landings were on the hindfoot, whereas forefoot contact with the ground only accounted for about $6 \%$ of all landings. The findings, however, were more in line with those reported by Steele and Milburn ${ }^{2}$ where $70 \%$ of the subjects in a laboratory-based experiment adopted a forefoot landing pattern.

The $14.3 \%$ of players who leapt to catch the ball in this study was substantially less than the $75.9 \%$ reported in the laboratory study by Steele and Milburn ${ }^{5}$. Most players approached the ball with a hop $(15.1 \%)$, jump $(24.7 \%)$ or had one foot planted on the ground $(25.0 \%)$.

Type of pass and direction of movements to receive the pass observed in this study were also different from the typical netball attacking movement patterns selected by Steele and Milburn ${ }^{6}$ for their laboratory study. In the controlled experiment, subjects were required to run forward, 'break' to a specified side to catch the ball, land on one leg, pivot and throw the ball to the catcher positioned $5-6 \mathrm{~m}$ away. In this match, nearly half of the passes were directed towards the players. Movement to the right or left was only required in $21.5 \%$ and $15.8 \%$ of the catches respectively.

There is evidence from this study that a variety of landing strategies are required for different positional play. Attacking, mid-field and defence players often landed on different sides of their feet. In addition, landing appeared to be affected by the type of pass, height of the catch and direction of movement. However, apart from the fact that far more forefoot landings were observed in this international match, no 'landing by position' comparison can be made as landing patterns have not previously been studied for different court positions.

The tactics of playing netball might have changed. Straight and relatively higher passes were used commonly in the game. This is certainly a contrast to the typical low passes used by Australian players more than a decade ago ${ }^{8}$. Our findings also indicated that overhead passes often resulted in forefoot landing but catches with one foot planted were used more than average for passes caught below the waist. This is consistent with data obtained by Steele and Milburn $^{2}$ who reported that most of the players (70\%) made initial contact with the forefoot upon landing when receiving a high pass, while only three of the ten players made initial contact with the heel of the foot on receiving this type of pass. Results from this study were also similar to results from Valiant and Cavanagh ${ }^{9}$ who found that in basketball the height of pass influenced the footfall patterns executed on landing.

\section{Acknowledgements}

The authors extend their appreciation to the Western Australian Netball Association for their generosity and support and for the access to the videotape. 
Landing patterns in netball: D. Hopper et al.

Table 5. Distributions of football patterns*

\begin{tabular}{|c|c|c|c|c|c|c|c|}
\hline & & \multicolumn{4}{|c|}{ Landing variable: footfall } & & \multirow[b]{2}{*}{$\mathrm{n}$} \\
\hline & & Fore & \multicolumn{2}{|c|}{ Hind } & \multicolumn{2}{|c|}{ Plant } & \\
\hline \multicolumn{8}{|l|}{ Type of pass } \\
\hline Straight & \multicolumn{2}{|r|}{66.3} & \multicolumn{2}{|c|}{8.7} & \multicolumn{2}{|c|}{25.1} & 403 \\
\hline Loop & & 82.8 & \multirow{2}{*}{\multicolumn{2}{|c|}{$\begin{array}{r}5.2 \\
14.9\end{array}$}} & \multirow{2}{*}{\multicolumn{2}{|c|}{$\begin{array}{l}12.1 \\
58.2\end{array}$}} & 58 \\
\hline Bounce & & 26.9 & & & & & 67 \\
\hline Rebound & & 100.0 & \multicolumn{2}{|c|}{0.0} & \multicolumn{2}{|c|}{0.0} & 5 \\
\hline \multicolumn{8}{|c|}{ Direction to catch pass } \\
\hline Straight & & & \multicolumn{2}{|c|}{3.7} & \multicolumn{2}{|c|}{36.8} & 272 \\
\hline Forward & & 51.0 & & & \multicolumn{2}{|c|}{29.4} & 51 \\
\hline Backward & & 100.0 & \multicolumn{2}{|c|}{0.0} & & & 6 \\
\hline Right & & 72.9 & \multicolumn{2}{|c|}{15.3} & & & 118 \\
\hline Left & & 67.4 & & & & & 86 \\
\hline Height of catch & & & & & & & \\
\hline Overhead & & 88.4 & & & & & 121 \\
\hline Head to waist & & 62.4 & & & & & 343 \\
\hline Below waist & & 25.7 & & & & & 70 \\
\hline & & & variabl & of foo & & & \\
\hline & Right & Left & Two-s & rical & Two-a & rical & $\mathbf{n}$ \\
\hline Movement direct & & & & & & & \\
\hline Straight & 28.3 & 22.7 & & & & & 286 \\
\hline Fonward & 40.3 & 35.5 & & & & & 62 \\
\hline Backward & 50.0 & 33.3 & & & & & 6 \\
\hline Right & 48.8 & 23.6 & & & & & 123 \\
\hline Left & 23.7 & 39.8 & & & & & 93 \\
\hline & & & ariable: & nent $p$ & & & \\
\hline & Hop & Leap/step & Jump & Skip & Run & Plant & $\mathbf{n}$ \\
\hline Type of pass & & & & & & & \\
\hline Straight & 15.9 & 13.3 & 29.7 & 9.7 & 7.1 & 24.2 & 421 \\
\hline Loop & 35.6 & 13.6 & 22.0 & 8.5 & 8.5 & 11.9 & 59 \\
\hline Bounce & 2.7 & 27.4 & 1.4 & 1.4 & 13.7 & 53.4 & 73 \\
\hline Rebound & 11.1 & 0.0 & 88.9 & 0.0 & 0.0 & 0.0 & 9 \\
\hline Direction to catcl & & & & & & & \\
\hline Straight & 8.5 & 6.0 & 31.7 & 11.3 & 7.0 & 35.6 & 284 \\
\hline Forward & 17.2 & 25.9 & 17.2 & 3.5 & 6.9 & 29.3 & 58 \\
\hline Backward & 33.3 & 50.0 & 16.7 & 0.0 & 0.0 & 0.0 & 6 \\
\hline Right & 29.0 & 21.8 & 24.2 & 5.7 & 8.0 & 11.3 & 124 \\
\hline Left & 20.7 & 22.8 & 18.5 & 6.5 & 12.0 & 19.6 & 92 \\
\hline Height of catch & & & & & & & \\
\hline Overhead & 16.0 & 14.5 & 58.0 & 2.3 & 3.8 & 5.3 & 131 \\
\hline Head to waist & 18.8 & 15.1 & 19.6 & 10.9 & 9.0 & 26.6 & 357 \\
\hline Below waist & 3.9 & 14.3 & 2.6 & 6.5 & 10.4 & 62.3 & 77 \\
\hline
\end{tabular}

No $\chi$-squares reported as all associations are significant (Table 4). *Read percentage across each row

\section{References}

1 Hopper D. A survey of netball injuries and conditions related to these injuries. Aust J Physiother 1986; 32: 231-9.

2 Steele JR, Milburn PD. A kinetic analysis of footfall patterns at landing in netball. Aust J Sci Med Sport 1989; 21: 10-13.

3 Lees A. Methods of impact absorption when landing from a jump. Eng Med 1981; 10: 207-11.

4 Steele JR, Lafortune MA. A kinetic analysis of footfall patterns at landing in netball: a follow-up study. In: Morrison WE, ed. Proceedings VII International Symposium of Biomechanics in Sports (Footscray Institute of Technology) 1989, 101-12.

5 Steele JR, Milburn PD. A kinematic analysis of netball landing techniques. Aust J Sci Med Sport 1987; 19: 23-7.

6 Steele JR, Milburn PD. Ground reaction forces on landing in netball. J Hum Mov Stud 1987; 13: 399-410.

7 Shrout PE, Fleiss JL. Intra-class correlations: uses in assessing rater reliability. Psych Bull 1979; 86: 420-8.

8 Brown J. Netball The Australian Way. Victoria, Australia: Stone Mill, 1978.

9 Valiant GA, Cavanagh PR. A study of landing from a jump; implications for the design of a basketball shoe. In: Winter DA, Norman RW, Wells RP, Hayes KC, Patla AE, eds. Biomechanics IX-B International Series on Biomechanics. IL, USA: Human Kinetics, 1985. 